Gut, 1969, 10, 730-734

\title{
Action of gastrin on the lower oesophageal sphincter in man
}

\author{
G. R. GILES, M. C. MASON, C. HUMPHRIES, AND \\ C. G. CLARK \\ From the Departments of Surgery, University of Leeds, and \\ University College Hospital Medical School, London
}

SUMMARY Both hog gastrin and synthetic gastrin stimulate the cardiac sphincter to increase tone and augment the resistance to reflux. Endogenous gastrin has a similar effect, and gastrin also stimulates the secretion of acid which has also been found to increase the resistance of the sphincter, but the effect of gastrin appears to be independent of the secretory stimulus.

Now that the role of gastrin in the control of gastric acid secretion has become clearer, attention has turned to the subsidiary action of this hormone on the smooth muscle of the gastrointestinal tract. Early studies by Blair, Harper, Lake, Reed, and Scratcherd (1961) showed that an extract of antral mucosa produced a marked pressor response in the stomach and upper small intestine of anaesthetized cats. Similar results were later reported by Gregory and Tracy (1964) using an extract of hog antral mucosa to produce stimulation of intestinal motility in dogs.

In an earlier study (Giles, Humphries, Mason, and Clark, 1968) we found that the intraluminal pressure of the cardiac sphincter increased when the gastric aspect of the sphincter mucosa was perfused with acid. This suggested a physiological response to gastric secretion such as after eating, and perhaps designed to increase the barrier pressure preventing gastrooesophageal reflux. Following this hypothesis it seemed reasonable to examine whether circulating gastrin, induced during eating, might have a similar effect.

In the experiments to be described, the pressures exerted by the lower oesophageal sphincter have been measured before and after the injection of hog gastrins I and II in varying doses, and also after injection of synthetic gastrin (ICI 50,123). The effect of release of endogenous gastrin can be studied in man using the technique of meat extract stimulation (Giles and Clark, 1967; Giles, Buchan, and Clark, 1967). This technique has been adopted to study the effect on the cardiac sphincter in an attempt to ascertain the events likely to occur during digestion.

\section{MATERIALS AND METHODS}

The methods used to measure the sphincteric pressures in these experiments were similar to those used previously (Giles et al, 1968) and measurements were made of the mean gastric pressure, maximum sphincteric pressure, and the oesophageal pressures, all calculated from the end expiratory measurements. After the sphincteric profile had been determined under resting control conditions, an injection of gastrin was given slowly intravenously and the sphincter profile was repeated after 15 minutes. The gastrin (Leo Labs) was given in a bodyweight dose which carried from 0.005 units to 1.0 units $/ \mathrm{kg}$.

In five subjects a continuous infusion of pentagastrin (ICI 50,123) was given at a rate of $0.06 \mu \mathrm{g} / \mathrm{kg} / \mathrm{hr}$ and sphincter profiles were obtained in the usual way after five and again after 25 minutes of infusion. In a further three subjects, pressure tracings were made before and 15 minutes after the introduction of $50 \mathrm{ml}$ of water into the stomach. After a further 15 minutes, $50 \mathrm{ml}$ of meat extract was introduced into the stomach, this latter stimulus being an affective stimulus of endogenous release of gastrin from the antrum (Welbourn and Burns, 1964; Giles and Clark, 1966 and 1967).

We have previously shown that when the gastric aspect of the cardia is in contact with hydrochloric acid there is an increase in the sphincteric pressures. Since some of the effects seen in the present experiments and attributed to gastrin could have been due to the action of concomitant stimulated acid on the cardia, the sphincteric pressures in three subjects were measured before and after the injection of Leo gastrin while at the same time perfusing the cardia with a weak bicarbonate solution.

All of the subjects tested were normal volunteers and 
considered on both clinical grounds and manometric investigation to have normal gastrooesophageal competence.

\section{RESULTS}

The pressure tracings obtained in these recordings have, as in the previous studies (Giles et al, 1968), been analysed entirely from the end expiratory pressure point because the pressures at the end inspiratory endpoint at any one tube position are too variable to be of real value. In Fig. 1 , tracings from two subjects are illustrated before and after a single intravenous injection of hog gastrin, with intragastric pressures being recorded to the left of the effective diaphragmatic hiatus $(H)$. In both subjects there is a marked rise in the sphincteric pressures and there is also some evidence of gastric peristalsis. This type of experiment was repeated with varying doses of gastrin.

The effect of a dose of 0.005 units $/ \mathrm{kg}$ of gastrin was to produce an overall increase in the maximum pressures exerted by the sphincter in all four subjects tested, with a rise from a mean of 8.5 to $12.3 \mathrm{~cm}$ of water. The mean sphincteric pressure profile and the maximum sphincteric pressures recorded are shown in diagrammatic form in Figure 2. Similarly in tests with a dose rate of 0.01 units $/ \mathbf{k g}$ of gastrin (Fig. 3) increases in the sphincteric pressures were again seen in all four subjects though less marked, the mean rising from 10.4 to $12.3 \mathrm{~cm}$ of water. With a dose of 0.1 units $/ \mathrm{kg}$ of gastrin used in three subjects (Fig. 4) only two had clear-cut increases in pressures and the mean maximum sphincteric pressure rose from 6.7 to $8.2 \mathrm{~cm}$ of water. Larger doses of gastrin in four other subjects produced increases in the gastric pressure and three showed increases in sphincteric pressure though the mean

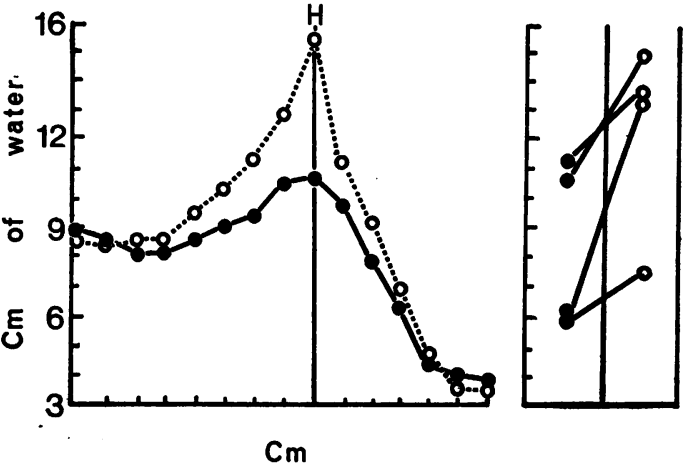

FIG. 2. Sphincter pressure profile obtained from the mean of four subjects before $(O)$ and after $(O)$ an intravenous dose of 0.005 units $/ \mathrm{kg}$. The maximum sphincter pressures are illustrated on the right.

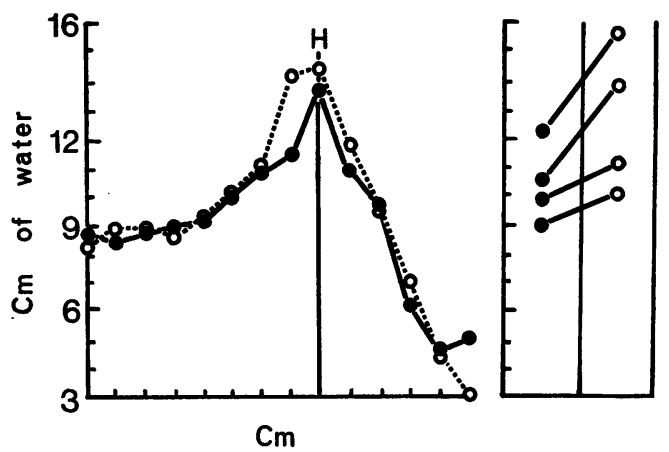

FIG. 3. Sphincter pressure profile obtained from the mean of four subjects before $(O)$ and after $(O)$ an intravenous dose of 0.01 units $/ \mathrm{kg}$.

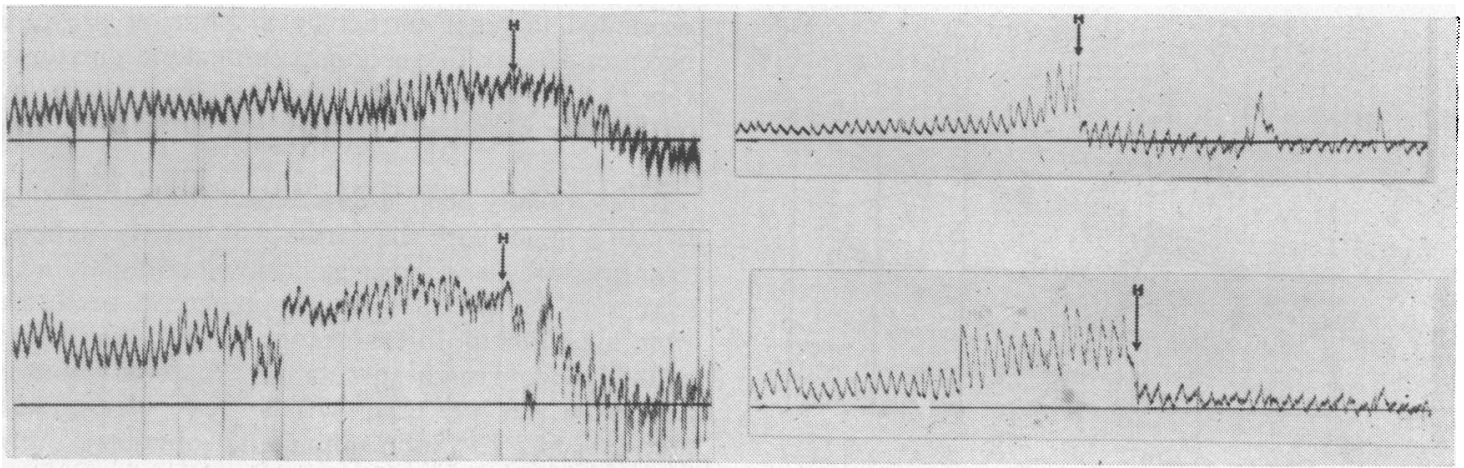

FIG. 1. Sphincter profile in two subjects (a and b) before (upper tracings) and after (lower tracings) intravenous injection of gastrin. Subject a received 0.5 units $/ \mathrm{kg}$ Leo gastrin; subject $\mathrm{b}$ received $0.05 / \mathrm{kg}$ Leo gastrin. $\mathrm{H}$ denotes the point of respiratory reversal. 


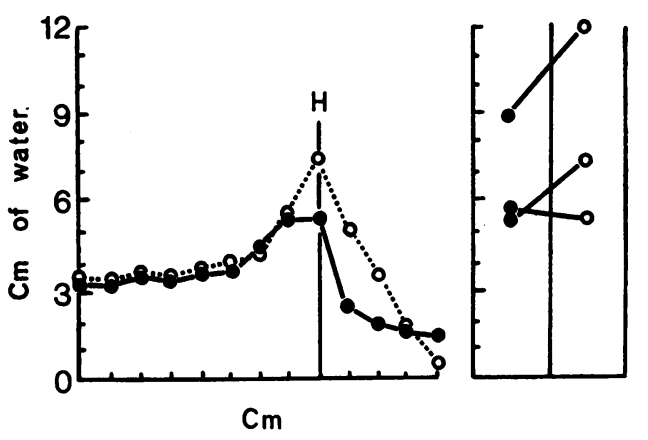

FIG. 4. Sphincter pressure profile obtained from the mean of four subjects before $(O)$ and after $(O)$ an intravenous dose of $0 \cdot 1$ units $/ \mathrm{kg}$.

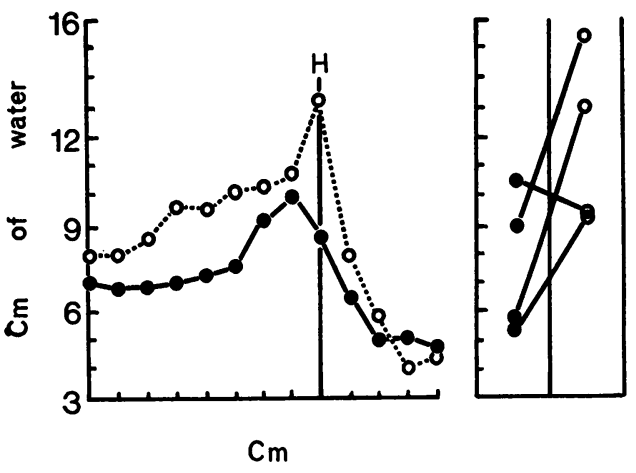

FIG. 5. Sphincter pressure profile obtained from the mean of four subjects before $(\circlearrowleft)$ and after $(\bigcirc)$ an intravenous dose of 1.0 units $/ \mathrm{kg}$.

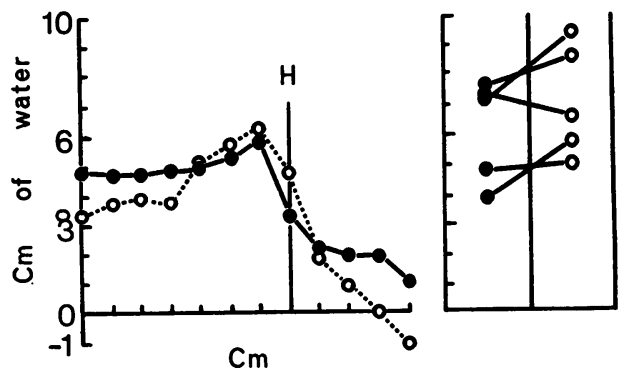

FIG. 6. Sphincter pressure profile obtained from the mean of four subjects before $(\Theta)$ and after $(O)$ a continuous infusion of pentagastrin in a dose of $0.6 \mathrm{ug} / \mathrm{kg} / \mathrm{hr}$. The maximum sphincter pressures are illustrated on the right. pressure rose only slightly from 8.5 to $9.6 \mathrm{~cm}$ of water. Finally with a dose of 1.0 units/kg (Fig. 5), three of four subjects produced marked increases in the sphincteric and gastric pressures with a mean rise from 7.7 to $11.8 \mathrm{~cm}$ of water. In two of these subjects the experiment was repeated on a different day, half an hour after intravenous injection of $1.2 \mathrm{mg}$ of atropine sulphate. Though gastrin had produced an increase in sphincteric pressure on the previous occasion, this effect was abolished by the action of the atropine. Throughout these experiments no changes were recorded in the intraoesophageal pressures. Gastric peristalsis and increases in intragastric pressure were usually only seen with the larger doses of gastrin. It was, therefore, concluded that hog gastrins I and II could affect the lower oesophageal sphincter in a manner liable to increase the barrier to reflux.

In five normal subjects the terminal pentapeptide ICI 50,123 was given by a continuous intravenous infusion at a dose rate of $0.6 \mu \mathrm{g} / \mathrm{kg} / \mathrm{hr}$ (single intravenous doses of this drug are not recommended by the manufacturers). Sphincteric pressures were recorded before infusion, after five minutes of infusion, and again after 25 minutes. The responses with this drug were variable with increases in sphincteric pressure in three subjects and slight falls in the other two and little change in the mean values. There was no difference in the responses after five minutes and those obtained with more prolonged infusion and tachyphlaxis was not seen (Fig. 6).

In order to demonstrate the effect of endogenous gastrin on the lower oesophageal sphincter a number of tests were carried out in which the sphincteric pressures were first measured under control conditions, then after the introduction of $50 \mathrm{ml}$ meat extract. Only minor and insignificant changes were seen after the introduction of water, but all subjects responded to meat extract by a sphincter pressure increase. The mean maximum sphincteric pressures were $11.8 \mathrm{~cm}$ in the control test, $13.7 \mathrm{~cm}$ after water, and $19.2 \mathrm{~cm}$ after the meat extract stimulation (Fig. 7).

It has already been shown (Giles et al, 1968) that acid in contact with the cardia will increase sphincteric pressures, and, since gastrin will stimulate acid secretion, the effects seen in sphincteric pressures after injection of this hormone could have arisen indirectly from such stimulation. In three subjects the cardia was perfused with a weak bicarbonate solution $(4.2 \%)$ and sphincteric pressures were measured before and after the injection of gastrin at a rate of $0.25 \mu \mathrm{g} / \mathrm{kg}$. Increases in pressure were seen in all three subjects and the mean pressure rose from $5 \cdot 2$ to $7 \cdot 2 \mathrm{~cm}$ of water. 

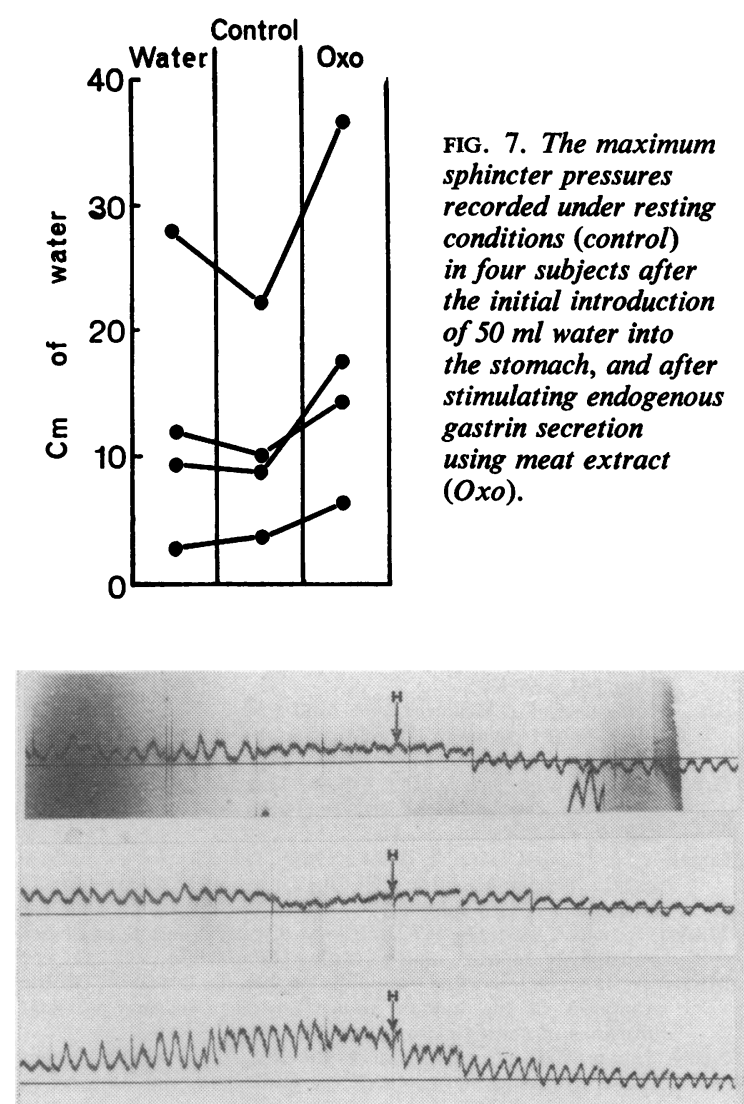

FIG. 8. Sphincter profile in a patient with achlorhydria showing no high pressure zone under control conditions (top tracings) or after 0.1 units/kg of gastrin (middle tracing). When 1.0 units/kg of gastrin is given the manometric features of a sphincter appear (lowest tracing).

Unfortunately it has not yet proved possible to measure sphincteric pressure in a patient with pernicious anaemia. However, Fig. 8 shows the effect on the sphincter profiles in a patient who five years before had undergone a partial gastrectomy and vagotomy and now had a iistamine and gastrin fast achlorrhydria. Under control conditions and after an injection of gastrin $(0.1 \mu \mathrm{g} / \mathrm{kg})$ there was little evidence of a high pressure zone and apparently no effective sphincter. When a dose of 1.0 unit $/ \mathrm{kg}$ was given, a zone of high pressure appeared which had all the manometric features of a lower oesophageal sphincter.

\section{DISCUSSION}

The action of gastrin on the smooth muscle of the gastrointestinal tract has been investigated by studies in vitro and in vivo. Studies in vitro have been concerned with the activity and contraction of strips of smooth muscle taken from experimental animals and man. In preparations from the stomach, duodenum, and the ileum of the rat and guinea pig increased contractions were produced by gastrin II (Bennett, 1965) and similar findings were reported by Miklos and Vane (1967) using muscle strips from the stomach and colon of the hamster. Experiments with muscle strips from human organs have been reported by Bennett, Misiewicz, and Waller (1967) showing that the oesophageal, gastric, terminal ileal, and colonic smooth muscle are all capable of responding to physiological doses of gastrin and pentagastrin though the response to the synthetic drug was less marked than to pure gastrin.

Studies in vivo in the dog (Gregory and Tracy, 1964) and the cat (Neely, 1967) have shown that gastrin and pentagastrin have a marked effect in stimulating gastrointestinal motility in the experimental animal. Smith and Hogg (1966), using a pressure-sensitive telemetering device in man, found that gastrin II exerted a significant effect on gastrointestinal motility, particularly the terminal ileum. The threshold dose, however, was higher than that needed to produce gastric secretory responses. Studies with pentagastrin in man (Logan and Connell, 1966) have shown a motor response in the small intestine which was not specific, but the activity of the colon was unequivocally increased in the distal segments. In a recent study by Misiewicz, Holdstock, and Waller (1967) pentagastrin was given in doses sufficient to increase the gastric acid to near maximal levels. While the motor activity of the gastric antrum was stimulated, the right and left colon were unresponsive and they suggested that the motor effects of pentagastrin might well be confined to the stomach.

There is little work as yet as to the effect of gastrin on smooth muscle sphincters. In the present study the pressures of the lower oesophageal sphincter were measured before and after an injection of hog gastrins given on a body weight dosage. In the majority of subjects there was an increase in the sphincteric pressures particularly with the larger doses. It is likely that even the larger doses were within the physiological range since we have previously shown that the same batch of Leo gastrin produced acid stimulation to about $70 \%$ of the maximal acid output when a dose of 1.0 units $/ \mathrm{kg}$ was used (Giles and Clark, 1967). Somewhat surprisingly, marked responses were also seen with the lower doses $(0.005$ units $/ \mathrm{kg})$ which in our studies of acid secretion in patients with duodenal ulcer stimulated to about $35 \%$ of the maximal acid output. Similarly the response to the meat extract 
stimulation was also marked and this response has also previously been shown to stimulate acid secretion to about $40 \%$ of the maximum in both normal subjects and patients with duodenal ulcer. The present results confirm the observations of Misiewicz et al (1967) and of Logan and Connell (1966) that the motor effects of pentagastrin on the cardiac sphincter are less obvious than those seen after injection with gastrin; nevertheless, three of the five subjects tested with pentagastrin showed an increase in the sphincteric pressures.

Since previous work has shown that acid in contact with the inferior aspect of the sphincter would produce an increase in the sphincter tone (Giles et al, 1968) the effects of gastrin could have been due to the action of stimulated acid. However, even when the cardia was perfused with sodium bicarbonate to counteract the effects of stimulated acid, the increases in sphincteric pressure were still seen. Furthermore, the restoration of a normal manometric pattern in the sphincteric area in a patient who was completely achlorhydric after a partial gastrectomy and vagotomy is conclusive evidence that gastrin can act on the lower oesophageal sphincter. Whether these increases in pressure have relevance to the preservation of normal oesophageal competence is still conjectural but it is interesting that several workers have reported a higher incidence of oesophageal reflux after partial gastrectomy where the gastric antrum, the source of endogenous gastrin, is removed (Bingham, 1958; Cox, 1961; Windsor, 1964).

It is unlikely that the pressure increases seen after injection of gastrin would be capable of resisting very large increases in intragastric pressure. However, it seems teleologically sound to suppose that the stimulation of gastrin and acid after a meal leads to an increase in the sphincteric pressures which is able to counteract the tendency to reflux at this time when gastric acid stimulation is at a maximum.

\section{REFERENCES}

Bennett, A. (1965). Effect of gastrin on isolated smooth muscle preparations. Nature (Lond.), 208, 170-173.

_- Misiewicz, J. J., and Waller, S. L. (1967). Analysis of motor effects of gastrin and pentagastrin on the human alimentary tract in vitro. Gut, 8, 470-474.

Bingham, J. A. W. (1958). Oesophageal strictures after gastric surgery and naso-gastric intubation. Brit. med. J., 2, 817-819.

Blair, E. L., Harper, A. A., Lake, H. J., Reed, J. D., and Scratcherd, T. (1961). A simple method of preparing gastrin. J. Physiol. (Lond.), 156, 11-13P.

Cox, K. R. (1961). Oesophageal stricture after partial gastrectomy. Brit. J. Surg., 49, 307-313.

Giles, G. R., and Clark, C. G. (1960). Gastric secretion stimulated by meat extract in man. Scand. J. Gastroent., 1, 159-166.

- Clark, C. G., and Buchan, R. (1968), The effect of oesophageal perfusion with acid on basal gastric secretion. Gut, 9, 52-56.

-, (1967). Circulating gastrin in peptic ulcer disease. Brit. J Surg., 54, 834-838.

- Humphries, C., Mason, M. C., and Clark, C. G. (1968). The effect of $p \mathrm{H}$ changes on the cardiac sphincter. Gut, to be published.

Gregory, R. A., and Tracy, H. J. (1964). The constitution and properties of two gastrins extracted from hog antral mucosa. Gut, 5, 103-114.

Logan, C. J. H., and Connell, A. M. (1966). The effect of a synthetic gastrin-like pentapeptide (ICI 50,123 ) on intestinal motility in man. Lancet, 1, 996-999C.

Miklos, E., and Vane, J. R. (1967). Effects of gastrin and its analogies on isolated smooth muscles. Nature (Lond.), 214, 105-107.

Misiewicz, J. J., Holdstock, D. J., and Walker, S. L. (1967). Motor responses of the human alimentary tract to near-maximal infusions of pentagastrin. Gut, 8, 463-469.

Neely, Julian (1967), Comparison of the effects of a gastrin extract and a synthetic pentapeptide on gastrointestinal motility in the cat. Gut. 8, 242.

Smith, A. N., and Hogg, D. (1966). Effect of gastrin II on the motility of the gastrointestinal tract. Lancet, 1, 403-404.

Welbourn, R. B., and Burns, C. P. (1964). The choice of operation for duodenal ulcer on the basis of pre-operative gastric studies. Proceedings of the Seventh International Congress of Gastroenterology, p. 163.

Windsor, C. W. O. (1964). Gastro-oesophageal reflux after partial gastrectomy. Brit. med. J., 2, 1233-1234. 